\title{
EFEITOS DE SURFACTANTES NA ORGANOFILIZAÇÃO DE ARGILAS BENTONÍTICAS PARA USO EM FLUIDOS DE PERFURAÇÃO DE BASE MICROEMULSIONADA
}

\author{
A. I. C. GARNICA ${ }^{1 *}$, F. D. S. CURBELO ${ }^{1}$, R. R. MAGALHÃES ${ }^{1}$, R. P. F. SOUSA ${ }^{1}$ \\ Universidade Federal da Paraíba \\ alfredocurbelo@yahoo.com*
}

Submetido 14/03/2018 - Aceito 05/09/2018

DOI: $10.15628 /$ holos.2018.7089

\section{RESUMO}

A principal indústria consumidora da argila bentonítica é a indústria petrolífera, pois a utiliza como viscosificante de fluidos de perfuração tanto base água quanto base óleo, sendo, neste último, necessário submeter o argilomineral a um processo conhecido como organofilização. Os fluidos não aquosos apresentam grande aplicabilidade, entretanto possuem um alto custo e elevada toxicidade. É nesse contexto, que os fluidos microemulsionados estão sendo desenvolvidos, para a faixa de aplicação dos fluidos de base não aquosa, visando um menor custo e baixa toxicidade. Nesse sentido, este trabalho teve como objetivo avaliar a interação de argilas organofilizadas pelos tensoativos Ultranex NP-40, Tween 80 e Praepagen, com dois meios microemulsionados do tipo água em óleo $(A / O)$, sendo a
\end{abstract}

fase oleosa do sistema I, a n-parafina e do sistema II, o óleo de pinho. $O$ estudo se iniciou com a construção dos diagramas de fases de cada sistema. As argilas organofílicas e in natura foram analisadas por difração de raio $X(D R X)$ e inchamento de Foster. Pelo DRX, pôdese observar um aumento na distância interplanar das argilas organofílicas, em relação a argila in natura $(14,46$ Å). No inchamento de Foster, observou-se que a microemulsão de $n$-parafina foi a que apresentou maior interação com as argilas modificadas. Os resultados mostraram que a argila organofilizada com Praepagen apresentou os melhores resultados, uma distância interplanar de 49,08 $\AA$ e um inchamento alto na microemulsão de parafina.

PALAVRAS-CHAVE: Argila bentonítica, organfilização, microemulsão, fluidos de perfuração microemulsionados.

\section{EFFECTS OF SURFACTANTS IN THE ORGANOPHILIZATION OF BENTONITE CLAYS FOR USE IN DRILLING FLUIDS BASED MICROEMULSIONS}

\begin{abstract}
The main consumer industry of bentonite clay is the oil industry, because it is a viscosifier for drilling fluids, both water based and oil based, being, in the latter, necessary to subject the clay to a process known as organophilization. Nonaqueous drilling fluids shows large applicability, however have a high cost and high toxicity. Is in this context that drilling fluids based in microemulsions are being developed, for the range of applicability of nonaqueous drilling fluids, aiming a lower cost and low toxicity. In this sense, this work aimed to evaluate the interaction between clays organophilized by surfactants Ultranex NP-40, Tween 80 and Praepagen, with two microemulsified systems of type water in oil (W/O), being the oil phase of system I,
\end{abstract}

the n-paraffin and of system II, pine oil. The study started with the construction of phase diagrams for each system. The clays organophilic and in natura were analyseds by X-ray diffraction (XRD) and Foster swelling. By XRD it was possible to observe an increase in the interplanar distance of organophilic clays, in comparison of the clay in natura (14.46 ̊). In the Foster swelling, was observed that the paraffin microemulsion showed the greater interaction with the modified clays. The results showed that the clay organophilized by Praepagen showed better results, with an interplanar distance of $49.08 \AA$ and a high swelling in paraffin microemulsion.

KEYWORDS: Bentonitic clay, organophilization, microemulsion, microemulsion drilling fluids. 


\section{INTRODUÇÃO}

As bentonitas são argilas esmectitas extremamente versáteis e apresentam uma extensa aplicação industrial. A principal indústria consumidora dessa esmectita é a petrolífera, pois a argila apresenta propriedades reológicas excepcionais, além de ser um material de baixo custo. Para os fluidos de perfuração de base aquosa, a argila é usada como viscosificante e, como parte do fluido, a argila emprega algumas características físicas importantes para o desempenho de suas funções, as quais incluem a suspensão dos cascalhos, a manutenção da estabilidade do poço e o resfriamento e lubrificação da broca (Caenn e Chillingar, 1996).

Em operações de perfuração na qual o fluido base aquosa se torna limitante, como em poços HTHP (altas temperaturas e altas pressões) ou poços de formações subterrâneas sensíveis à água, faz-se necessário o uso de fluidos de base não-aquosa. Para esse tipo de fluido, a bentonita perde a suas propriedades tixotrópicas devido à natureza hidrofílica dessas esmectitas. Nesses casos, as argilas devem passar por um tratamento químico, denominado organofilização. As argilas organofílicas que contém moléculas orgânicas intercaladas entre suas camadas estruturais ou adsorvidas na superfície. Tais moléculas orgânicas são cedidas pelos tensoativos, que podem ser iônicos, não iônicos e anfóteros, e, por sua vez, provocam uma expansão entre os planos da argila, mudando a sua natureza (Santos et al., 2002).

Por outro lado, existe uma grande demanda em pesquisas para o desenvolvimento e aprimoramento de fluidos base oleosa e base sintética, voltados à preservação do meio ambiente. Com isso, o desenvolvimento de novos fluidos de perfuração precisa abranger as características dos sistemas de fluidos base aquosa em relação à baixa toxicidade, porém precisam apresentar características específicas de fluidos base óleo, com o intuito de otimizar a perfuração e cumprir as restrições ambientais (Araújo, 2015). Assim, têm-se buscado a substituição de óleos utilizados na indústria para preparação de fluidos de perfuração, tais como o diesel, que é bastante tóxico, por óleos menos tóxicos, como a n-parafina e os óleos vegetais.

Segundo Son (1973), fluidos de perfuração feitos a partir de bases microemulsionadas contribuem para uma maior estabilidade do poço, quando comparado ao mesmo preparado a partir de emulsões, além de serem estáveis termodinamicamente, espontâneos e facilmente preparáveis. Pesquisadores como Hayes, Haws e Gogarty (1977), Davies, Meeten e Way (1997), Quintero et al., (2009) e Curbelo et. al, (2017) estudaram a aplicação dessa base em fluidos de perfuração e observaram vantagens como: ser estável em uma ampla faixa de condições salinas, ser resistentes à corrosão, terem boas características de lubricidade, força gel, formação de reboco menos permeável e fino e possuir baixa tensão interfacial.

Diante do exposto, esse trabalho teve por objetivo a análise da influência de tensoativos iônicos e não iônicos na organofilização de argilas bentoníticas para aplicação em fluidos de perfuração microemulsionados do tipo água em óleo (A/O). Foram avaliadas também a interação da argila organofílica com as bases microemulsionadas desenvolvidas e com as fases oleosas utilizadas na preparação das microemulsões, sendo elas um óleo vegetal, o óleo de pinho; e um óleo mineral, a n-parafina. 


\section{REVISÃO BIBLIOGRÁFICA}

\subsection{Argilas bentoníticas}

As argilas são materiais naturais, formadas quimicamente por silicatos hidratados de alumínio, ferro e magnésio, de granulação fina. As partículas cristalinas que as constitui são extremamente pequenas, de diâmetro inferior a $2 \mu \mathrm{m}$, compostas por um número restrito de minerais conhecidos como argilomineral (Santos, 1989).

No caso particular das argilas bentoníticas, tais argilas são constituídas basicamente pelo argilomineral montmorilonita, cuja fórmula química geral é $\mathrm{M}_{\mathrm{x}}\left(\mathrm{Al}_{4-\mathrm{x}} \mathrm{Mg}_{\mathrm{x}}\right) \mathrm{Si}_{8} \mathrm{O}_{20}(\mathrm{OH})_{4}$. Geologicamente, ela é considerada como um produto de alteração de cinzas vulcânicas e, atualmente, já é aceito como bentonita qualquer argila esmectítica que possua propriedades semelhantes as bentonitas estrangeiras originárias de cinzas vulcânicas (Ferreira, 2009). No entanto, tal definição pode mudar de acordo com a formação técnica e científica de quem a utiliza (geólogos, químicos, engenheiros etc).

A bentonita, do grupo das esmectitas, é formada por duas folhas de silicato tetraédricas, com uma folha central octaédrica, unidas entre si por oxigênios comuns às folhas, como pode ser observado na Figura 1 (Santos, 1989). O empilhamento dessas placas ocorre por forças fracas e por forças de van der Waals. Os espaços entre as placas são denominados de galerias ou camadas intermediárias interlamelares, nas quais estão cátions trocáveis, como $\mathrm{Na}^{+}, \mathrm{Ca}^{2+}, \mathrm{Li}^{+}$, fixos eletrostaticamente e com a função de compensar cargas negativas geradas por substituições isomórficas que ocorrem no reticulado (Silva e Ferreira, 2008).

A troca iônica (Figura 1) desses cátions por cátions orgânicos, permite a modificação da superfície através de um processo chamado de organofilização.

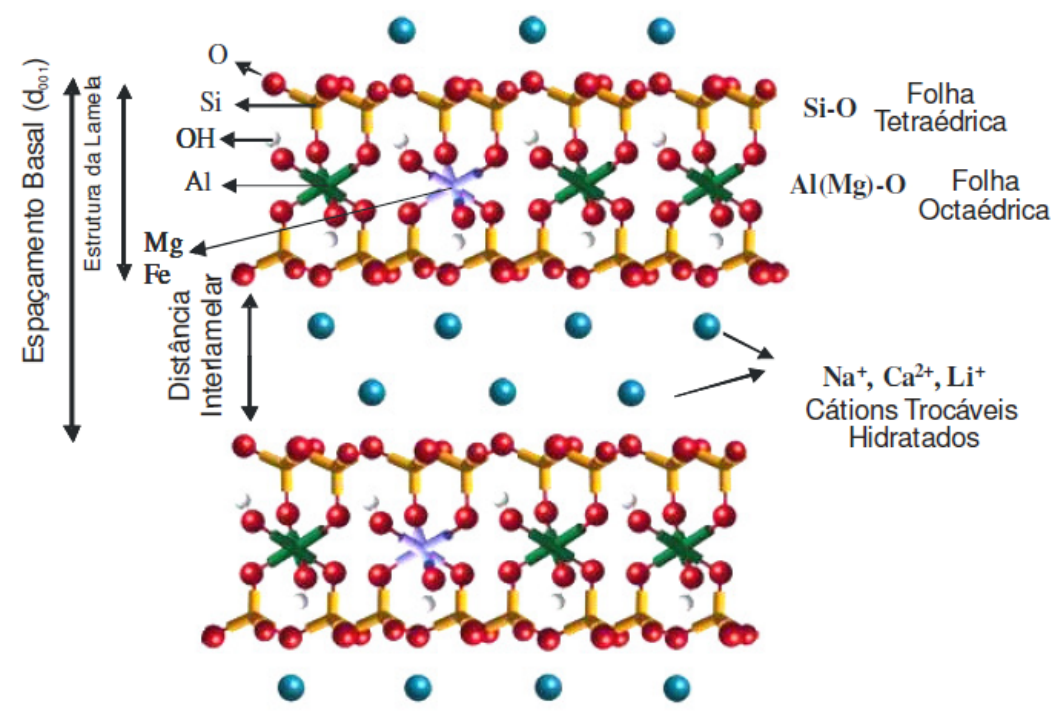

Figura 1: Estrutura da argila bentonítica "in natura" (Ferreira, 2009 - Adaptado).

\subsubsection{Argilas organofilicas}

Através de tratamentos específicos com tensoativos, as argilas bentoníticas, de natureza hidrofílica, podem ser modificadas. Bentonitas organofílicas são argilas que podem ser sintetizadas 
a partir de bentonita sódica ou cálcica, pela adição de tensoativos com ao menos uma cadeia contendo 12 ou mais átomos de carbono, em dispersões aquosas de argila (Barbosa et al., 2006).

No caso de tensoativos iônicos, o mecanismo para interação com as bentonitas ocorre através da troca iônica dos cátions. Nesta técnica é feita a modificação superficial da bentonita com a substituição de cátions trocáveis presentes na argila (Figura 1), por cátions orgânicos de tensoativos iônicos (Paiva e Morales, 2007). A substituição desses cátions, altera a distância interplanar do argilomineral, como pode ser verificado na Figura 2. Para os tensoativos não iônicos, a modificação ocorre através dos fenômenos de adsorção, sendo as ligações de hidrogênio a principal força motriz para essa adsorção. Esse processo torna a superfície das lamelas individuais hidrofóbica (Santos et al., 2002).

Assim, a modificação superficial da bentonita permite a aplicação desta em um maior leque de processos industriais (Silva et al., 2012), incluindo na formulação de fluidos de perfuração não aquosos. Nesse caso, a argila deve inchar em meio orgânico, fornecendo as propriedades físicas características desse argilomineral.
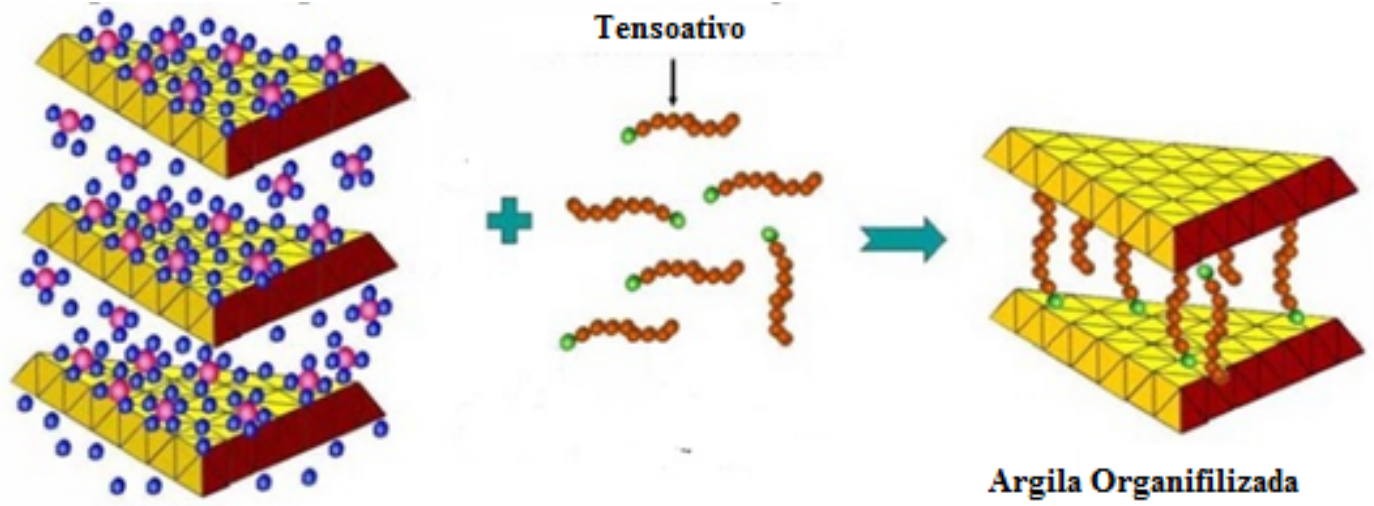

Argila Organifilizada

$$
\begin{aligned}
& \text { - Água } \\
& \text { O } \mathrm{Na}^{+}
\end{aligned}
$$

Figura 2: Esquema da organofilização de uma argila, onde moléculas do tensoativo foram introduzidas entre as lamelas (MARTINS et al., 2007 - Adaptado).

\subsection{Tensoativos}

Os tensoativos são substâncias muito importantes no ramo da Química. Isso é devido à sua característica de possuir afinidade tanto por água quanto por óleo, podendo pertencer aos dois meios. Sendo assim, os tensoativos, também chamados de surfactantes, podem ser utilizados como conciliadores dessas fases imiscíveis e, por isso, podem ser encontrados em diversos produtos da indústria química, como detergentes, fármacos, tintas e cosméticos (Daltin, 2011).

Os tensoativos são constituídos por moléculas orgânicas anfifílicas, devido à presença de grupos apolares (hidrofóbicos) e grupos polares (hidrofílicos) em uma mesma molécula. A parte hidrofóbica de um tensoativo é composta por uma cadeia carbônica linear ou ramificada. Apesar dos carbonos dessa cadeia serem mais eletronegativos que os átomos de hidrogênio, eles não geram polos de concentração de carga eletrostática. Já na parte hidrofílica, diferentemente da parte hidrofóbica, deve existir uma carga positiva ou negativa, mesmo que parcial, sendo 
responsável pela solubilidade da molécula tensoativa em água, uma vez que ocorrerá atração entre as cargas da parte polar do tensoativo e as cargas da molécula de água (Daltin, 2011).

Uma forma de caracterização dos tensoativos é quanto aos seus grupos polares que podem ser iônicos, não iônicos ou anfóteros.

\subsubsection{Microemulsão}

A microemulsão é formada por dois líquidos imiscíveis (água, óleo) na presença de tensoativo e, quando necessário, um cotensoativo. Tem como características ser um sistema disperso, monofásico, termodinamicamente estável, com baixa tensão superficial, transparente ou translúcido e possui a capacidade de combinar grandes quantidades de dois líquidos imiscíveis em uma única fase homogênea (Rossi et al., 2007). O tamanho das gotículas é responsável pela característica translúcida do sistema, já que o diâmetro médio das gotículas é menor do que 1/4 do comprimento de onda da luz. Com isso, as mesmas não espalham luz e o sistema fica transparente (Damasceno et al., 2011).

As microemulsões apresentam uma grande diversidade estrutural em função da sua composição química, no entanto, são apenas constituídas de microgotículas que variam seu diâmetro de 10 a $300 \mathrm{~nm}$. As microemulsões não apenas se diferenciam das emulsões pelo menor tamanho de partícula, mas, principalmente, pela estabilidade termodinâmica e por serem sistemas de formação espontânea (Aum, 2016).

Segundo Ho, Hsiao e Sheu (1996), uma tensão interfacial $\left(\gamma_{i}\right)$ muito baixa, geralmente menor que $10^{-7} \mathrm{~N} / \mathrm{cm}$, é um pré-requisito para a formação de um sistema microemulsionado (SME). Tem-se, pela lei da termodinâmica, expressa pela Equação (1), a energia livre de Gibbs (G), em que $\Delta S$ é a mudança da área interfacial, que não pode ser zero, ficando a cargo da tensão superficial determinar o $\Delta G$. Como $\gamma_{i}$ se aproxima de zero, podendo chegar a valores negativos para formar uma microemulsão, pode-se dizer que a energia livre de Gibbs tenderá a zero e, com isso, o sistema fica estável termodinamicamente $e$, quando $O \Delta G$ for negativo, a microemulsificação será espontânea (Damasceno et al., 2011).

$\Delta G=\gamma_{i} \Delta S$

\subsection{Fluido de Perfuração}

Os fluidos de perfuração, também conhecidos como lamas de perfuração, podem ser definidos como uma mistura complexa de sólidos, líquidos, componentes químicos e, algumas vezes, até de gases (Thomas, 2001).

Segundo Thomas (2001), os fluidos de perfuração devem possuir as seguintes características: serem estáveis quimicamente; estabilizarem as paredes dos poços, mecânica e quimicamente; facilitarem a separação dos cascalhos na superfície; manterem os sólidos em suspensão quando estiverem em repouso; não reagirem com as rochas produtoras; aceitarem 
qualquer tratamento, físico e químico; serem bombeáveis e apresentarem baixo grau de corrosão e de abrasão.

Em campo, as principais propriedades reológicas de interesse para o desenvolvimento de um fluido de perfuração são a viscosidade aparente, a viscosidade plástica, o limite de escoamento e a força gel. Segundo Shiroma (2012), essas são as propriedades reológicas mais importantes geradas pelo uso da bentonita como viscosificante. A finalidade de controlar essas propriedades é conseguir minimizar a pressão das bombas, maximizar a limpeza do poço, evitar influxo da formação e prevenir perda de circulação para a formação perfurada (Almeida e Silva, 2010).

De maneira geral, os fluidos de perfuração são classificados de acordo com sua fase contínua em fluidos base água, base ar ou gás e base óleo. Porém, devido à elevada toxicidade dos fluidos base óleo, uma nova classe de fluidos de perfuração surgiu, os fluidos sintéticos.

A nova geração de fluidos de perfuração, criados para as mesmas aplicações que os fluidos base óleo, são conhecidos como fluidos de base sintética, constituídos por líquidos sintéticos, tais como ésteres, éteres, polialfaolefinas, glicerinas, glicóis, glicosídeos e n-parafinas (Caenn e Chilingar, 1996).

Todavia, essas bases ainda apresentam alta toxicidade e baixa biodegradabilidade, além de altos custos. Nesse sentido, novas tecnologias na preparação do fluido visam minimizar os custos e os danos ao meio ambiente, bem como manter as propriedades do fluido sintético próximas às dos fluidos base óleo. Nesse sentido, destacam-se os estudos de Curbelo et al., (2016), voltados para o desenvolvimento de fluido de perfuração a partir de sistemas microemulsionado, que, além de possibilitar uma maior estabilidade do sistema, obteve excelentes resultados de viscosidade, lubricidade e volume de filtrado, fazendo uso de componentes não tóxicos na composição da microemulsão.

\section{METODOLOGIA}

\subsection{Preparação das microemulsões}

Para formação das microemulsões, inicialmente foi preciso determinar o comportamento de fases dos constituintes de cada microemulsão, através da construção de diagramas ternários, em que cada constituinte representa um vértice. O diagrama de fases ternário mostra a solubilidade dos componentes entre si, mostrando as fases do sistema e possibilitando a melhor escolha da composição do fluido de perfuração dentro da região de microemulsão.

Para preparação da microemulsão de parafina, foi utilizado uma salmoura com $2 \% \mathrm{NaCl}$ como fase aquosa, a parafina como fase oleosa e um tensoativo não iônico, Ultranex NP 40. Para a preparação da microemulsão de óleo de pinho, foi utilizado uma solução 1:1 de água e glicerina como fase aquosa, o óleo de pinho como fase oleosa e um tensoativo não iônico, Tween 80.

Os diagramas de fases foram preparados usando a metodologia de titulação da fração mássica, que se baseia em fixar a proporção de 2 componentes do diagrama, lado binário do 
triângulo, e titular com o terceiro componente (Figura 3), utilizando uma centrífuga para separação das fases, uma balança analítica e agitadores magnéticos. A temperatura de análise foi de $25^{\circ} \mathrm{C}$.

Os meios microemulsionados A/O foram preparados apenas pela agitação suave dos componentes nas frações mássicas pré-determinadas no diagrama, dentro da região de microemulsão com maior fração de fase oleosa $(A / O)$.

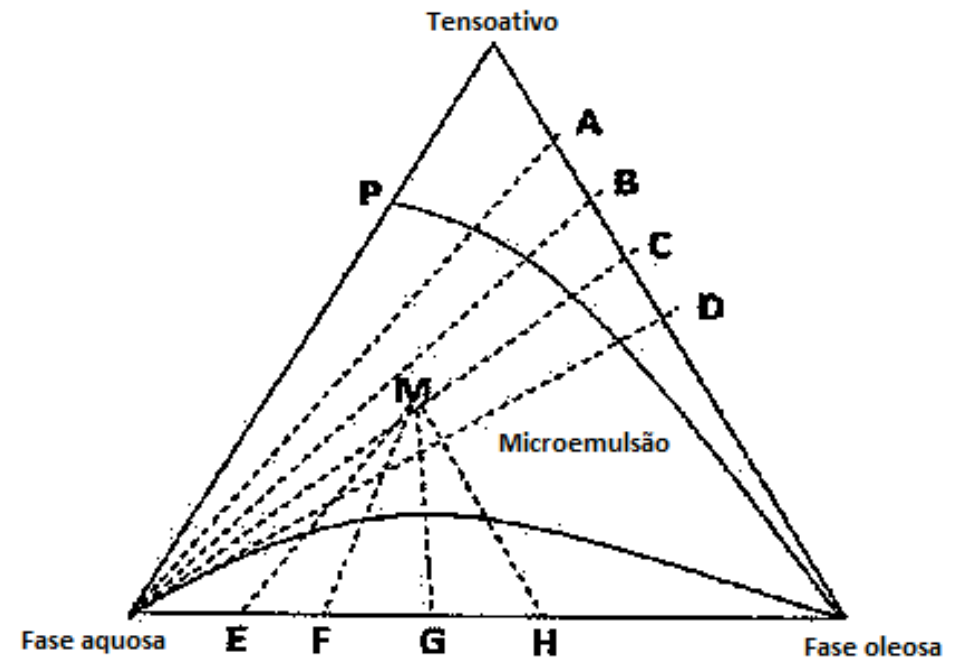

Figura 3: Diagrama de fases ternário esquematizado para determinar a região de microemulsão (Dantas Neto et al., 2011 - Adaptado).

\subsection{Modificação superficial da argila bentonítica}

Segundo a metodologia proposta por Ferreira (2009), foram preparadas dispersões contendo $500 \mathrm{~mL}$ de água destilada e 4,16\% de bentonita sódica. A argila foi adicionada lentamente, sob agitação constante, no agitador Hamilton Beach, numa velocidade de rotação de 10000 rpm. Após a adição de toda a argila, a agitação foi mantida por 20 minutos. Uma solução de tensoativo, previamente preparada, foi adicionada junto a bentonita, em concentrações de 20 e $30 \%$, relativos à massa de bentonita. 0 sistema foi mantido em agitação por mais 20 minutos. Os tensoativos estudados nesse processo estão apresentados na Tabela 1.

Tabela 1: Tensoativos utilizados na organofilização.

\begin{tabular}{c|c|c}
\hline Tensoativo & Tipo & Natureza \\
\hline Tween 80 & Não-iônico & Ácido oleico \\
Ultranex 40 & Não-iônico & $\begin{array}{c}\text { Nonilfenol } \\
\text { etoxilado } \\
\text { Praepagen WB }\end{array}$ \\
Catiônico & $\begin{array}{c}\text { Sal quaternário } \\
\text { de amônio }\end{array}$ \\
\hline
\end{tabular}


Para os tensoativos não-iônicos, foi necessário a adição de algumas gotas de $\mathrm{HCl} 2 \mathrm{M}$, até que o pH do sistema ficasse igual a 7, garantindo, dessa forma, uma maior facilidade na filtração. O material obtido foi, então, lavado para retirada do tensoativo em excesso, e filtrado em um funil de Buchner com kitassato acoplado a uma bomba de vácuo. Os aglomerados obtidos na filtração foram secos em estufa à $60^{\circ} \mathrm{C}$, por um período de $48 \mathrm{~h}$. Em seguida, com o auxílio de um almofariz, os aglomerados foram desagregados até a obtenção de partículas muito finas. Para garantir a homogeneidade granulométrica das partículas, estas foram submetidas ao peneiramento em peneiras ABNT no $200(0,074 \mathrm{~mm})$, sendo, posteriormente, caracterizadas.

\subsection{Difração de raio X (DRX)}

Com o objetivo de determinar o aumento do espaçamento basal, após o processo de organofilização, foram feitas análises de DRX na bentonita sódica "in natura" e nas organofilizadas, para cada um dos tensoativos apresentados na Tabela 1.

O equipamento utilizado foi o XRD 6000 da Shimadzu, que opera através da análise do cristal, no qual é emitido um feixe de radiação que irá difratar em um cristal de estrutura desconhecida, sendo a medida dos ângulos da difração dos raios utilizada para calcular a distância dos planos no cristal, obedecendo a lei de Bragg (Morais, Silva e Silva, 2017).

A lei de Bragg é representada pela Equação (2), a qual permite calcular a distância interplanar (d), através do ângulo de difração $(\theta)$, do número inteiro $(n)$ e do comprimento de onda dos raios $X$ incidentes $(\lambda)$ das argilas "in natura" e organofílicas.

$n \lambda=2 d \sin \theta$

A radiação utilizada foi $K \alpha$ do $\mathrm{Cu}$, a uma corrente de $30 \mathrm{~mA}$ e tensão de $40 \mathrm{kV}$. Esse processo foi feito usando uma velocidade do goniômetro de $0,5^{\circ} / \mathrm{min}$ e um passo de $0,02^{\circ}$.

\subsection{Inchamento de Foster}

As medidas de inchamento de Foster foram realizadas nos seguintes meios dispersantes: $n$ parafina, microemulsão com fase oleosa de n-parafina, óleo de pinho e microemulsão cuja fase oleosa é óleo de pinho. Este teste permite avaliar a compatibilidade dos agentes dispersantes com as argilas organofilizadas obtidas com os diversos tensoativos. Seguindo a metodologia proposta por Foster (1953) apud Ferreira (2009), em uma proveta de $100 \mathrm{~mL}$ foi adicionado $1 \mathrm{~g}$ da argila organofílica em $50 \mathrm{~mL}$ dos dispersantes estudados. O sistema foi deixado em repouso por $24 \mathrm{~h}$ e então, foi efetuada a leitura do inchamento sem agitação, através da medição do volume da argila na proveta. Após a leitura sem agitação, o sistema foi agitado mecanicamente e deixado em repouso por mais $24 \mathrm{~h}$. Ao fim deste período, foi efetuada a leitura do inchamento com agitação. $\mathrm{O}$ inchamento pode ser considerado: não inchamento, baixo, médio e alto inchamento, de acordo com o apresentado na Tabela 2. 
Tabela 2: Valores para identificação do inchamento de Foster (Pereira et al., 2007).

\begin{tabular}{c|c}
\hline Tipo de Inchamento & Valores $(\mathrm{mL} / \mathrm{g})$ \\
\hline Não inchamento & Igual ou inferior a 2 \\
Baixo & Acima de 2 a 5 \\
Médio & Acima de 5 a 8 \\
Alto & Acima de 8 \\
\hline
\end{tabular}

\section{RESULTADOS E DISCUSSÃO}

\subsection{Diagramas ternários}

Foram construídos dois diagramas ternários, sendo o sistema I composto por uma solução aquosa 2\% NaCl, parafina e Ultranex NP 40 (Figura 4); e o sistema II composto por uma solução 1:1 água e glicerina, óleo de pinho e Tween 80 (Figura 5). Observa-se, nas Figuras 4 e 5, a presença de uma região de microemulsão monofásica $(1 \phi)$ e de regiões de duas fases $(2 \phi)$ formadas por uma microemulsão em equilíbrio com excesso de fase aquosa ou fase de oleosa.

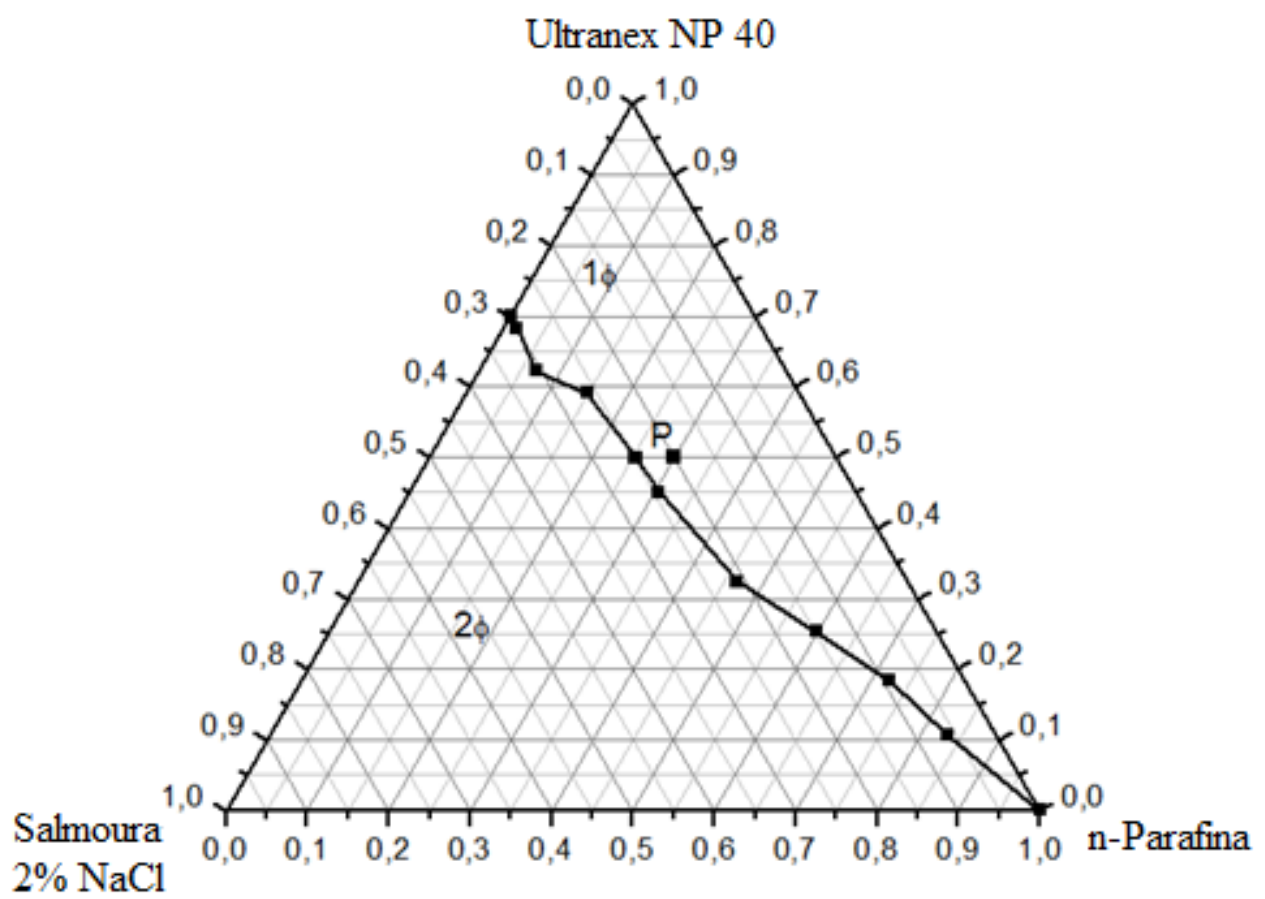

Figura 4: Diagrama ternário para o sistema I. 


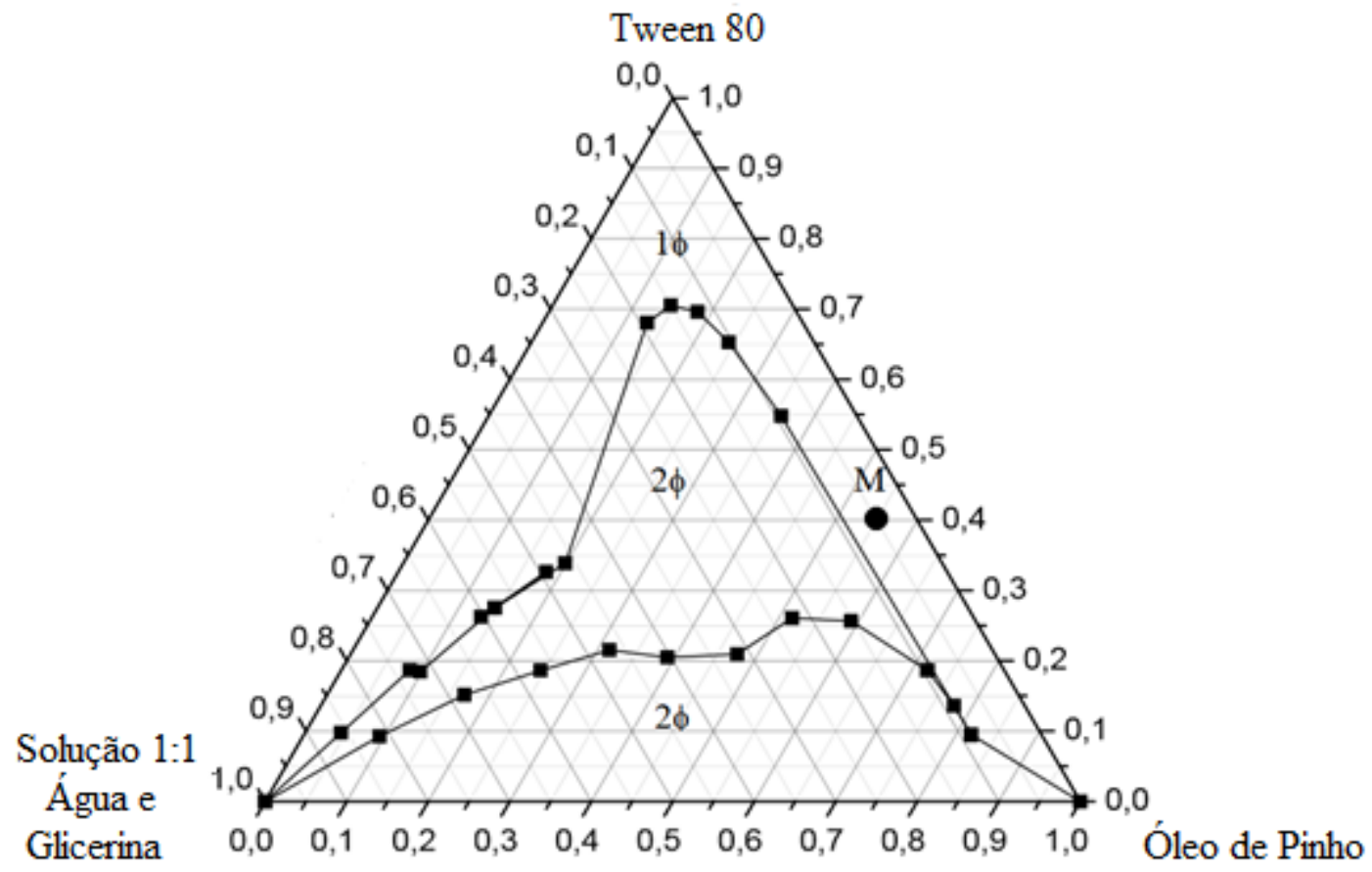

Figura 5: Diagrama ternário para o sistema II.

É importante destacar que a região monofásica (microemulsão) é a de interesse neste trabalho. Observando-se as regiões de microemulsão nos diagramas das Figuras 4 e 5, foram escolhidos o ponto $\mathrm{P}$ para o sistema I, cuja composição em massa é $50 \%$ de tensoativo, $20 \%$ de fase aquosa e $30 \%$ de fase oleosa; e o ponto M para o sistema II, cuja composição em massa é $5 \%$ da fase aquosa, $40 \%$ do tensoativo e $55 \%$ da fase oleosa. Estes sistemas foram utilizados para posterior análise no inchamento de Foster. A escolha dos pontos $\mathrm{P}$ e $\mathrm{M}$ seguiram a sistemática de obter microemulsões do tipo A/O, ou seja, microemulsões com predominância da fase oleosa.

\subsection{Difração de raios $X(D R X)$}

Na Figura 6 está apresentado o resultado da difração de raios $X$ da argila utilizada no processo de organofilização. Pelo difratograma observa-se que a amostra de bentonita sódica apresenta um pico de angulação $2 \theta 6,77^{\circ}$, característico das montmorilonitas, confirmando a natureza da mesma. Além desse pico, pode-se destacar os picos nos ângulos $2 \theta$ de $12,37^{\circ}, 19,9^{\circ}$, $20,9^{\circ}, 21,74^{\circ}$ e $26,7^{\circ}$ que, por sua vez, representam a presença de quartzo e caulinita, identificados na Figura 6. Estas angulações estão em concordância com o encontrado por Santos et al., (2002) para o mesmo argilomineral. 


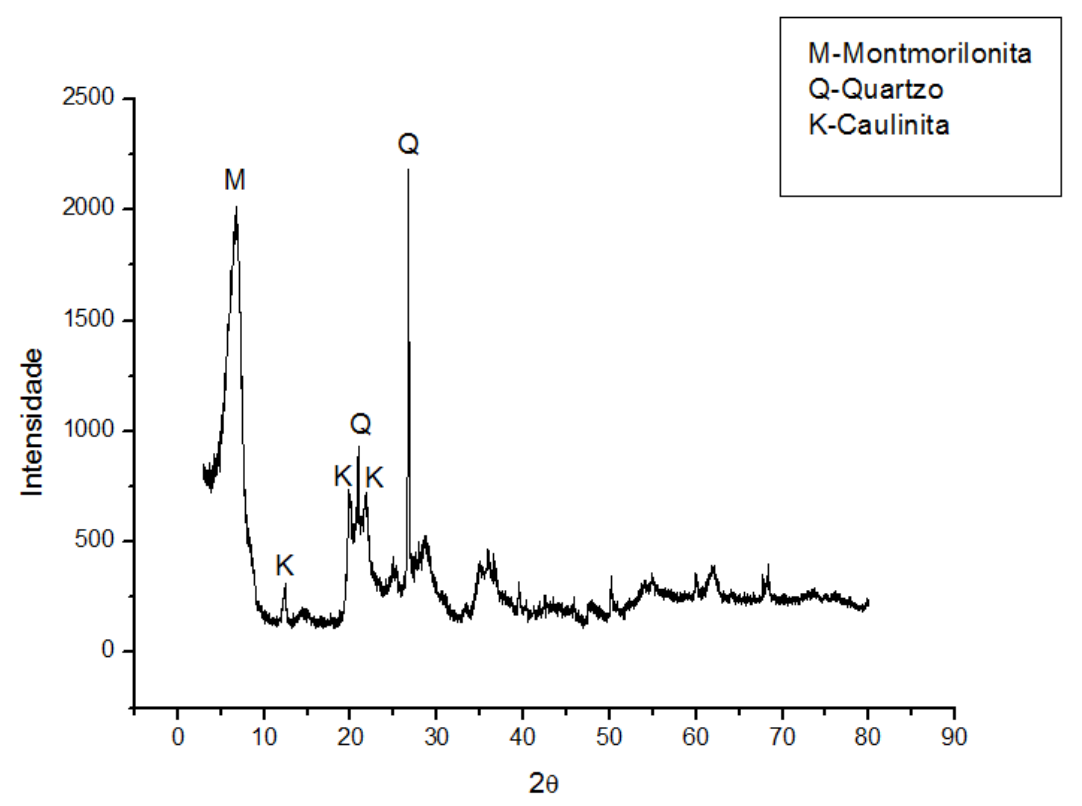

Figura 6: Difração de raio $X$ da argila cálcica in natura.

Pelas Figuras 7 e 8, foi possível observar a mudança no ângulo de difração da argila organofílica com a mudança de tensoativos, nas concentrações de $20 \%$ e $30 \%$, respectivamente, em relação ao difratograma da argila in natura e, por consequência, ocorre alteração na distância interplanar, a qual foi calculada pela Lei de Bragg, Equação (2), como apresentado pela Tabela 2.

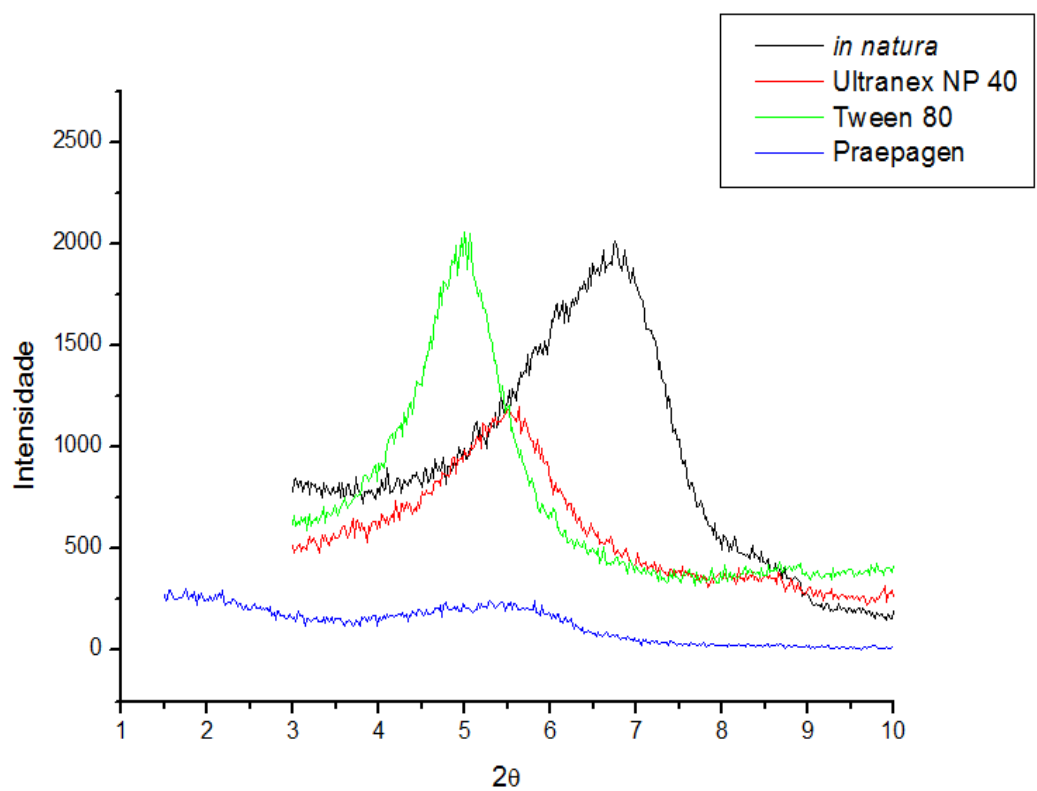

Figura 7: Comparação da difração de raio $\mathrm{X}$ da argila in natura com as organofilizadas pelos tensoativos: Ultranex NP40, Tween 80 e Praepagen, numa concentração de $\mathbf{2 0 \%}$. 


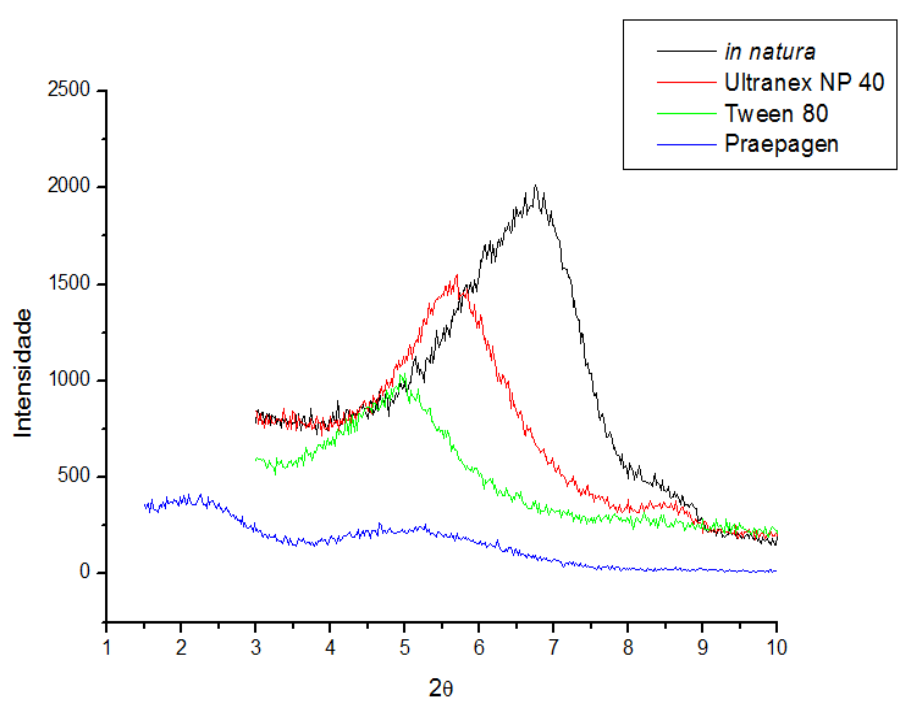

Figura 81: Comparação da difração de raio $X$ da argila in natura com as organoflizadas pelos tensoativos: Ultranex NP40, Tween 80 e Praepagen, numa concentração de $30 \%$.

Tabela 22: Resultados da DRX para os tensoativos estudados, nas concentrações de 20 e $30 \%$

\begin{tabular}{c|c|c|c|c}
\hline \multirow{2}{*}{ TENSOATIVO } & \multicolumn{2}{|c|}{$\mathbf{3 0 \%}$} & \multicolumn{2}{c}{$\mathbf{2 0 \%}$} \\
\cline { 2 - 5 } & $\mathbf{2 \theta}$ & $\begin{array}{c}\text { DISTÂNCIA } \\
\text { INTERPLANAR (Å) }\end{array}$ & $\mathbf{2 \theta}$ & $\begin{array}{c}\text { DISTÂNCIA } \\
\text { INTERPLANAR (Å) }\end{array}$ \\
\hline In natura & 6,79 & 14,46 & 6,79 & 14,46 \\
Ultranex NP 40 & 5,58 & 17,60 & 5,72 & 17,16 \\
Tween 80 & 4,95 & 19,83 & 5,05 & 19,48 \\
Praepagen & 2,20 & 44,62 & 2,0 & 49,08 \\
\hline
\end{tabular}

Para a análise da distância interplanar, é considerado apenas o primeiro pico das curvas. Sendo assim, pode-se observar, através das Figuras 6 e 7, que a curva da argila organofilizada com Praepagen encontra-se mais deslocada para esquerda, ou seja, com um menor ângulo de difração. Pela Equação (2), tem-se que o ângulo de difração é inversamente proporcional a distância interplanar, logo, pode-se afirmar que todos os tensoativos testados conseguiram organofilizar a argila bentonítica. Ainda de acordo com os difratogramas das Figuras 6 e 7 e pela Tabela 2, o Praepagen provocou um espaçamento basal mais significativo para as duas concentrações estudadas, em comparação aos outros tensoativos.

De acordo com Paiva, Morales e Diaz (2008), a alta distância basal alcançada pelo Praepagen pode ser justificada pelo fato de tal surfactante ser catiônico, permitindo assim a substituição do sódio, presente nas argilas sódicas, pelo sal quaternário de amônio. Como os outros tensoativos são não iônicos, ocorreu a impossibilidade da síntese da organofilização pela 
troca catiônica. No caso desses tensoativos, a organofilização se dá pelo fenômeno da adsorção, onde as pontes de hidrogênio são consideradas a principal força motriz para esse processo (Silva et al., 2012).

\subsection{Inchamento de Foster}

De acordo com os resultados do aumento do espaço interlamelar, avaliados pelo DRX, pôde-se perceber que não houve variação significativa no aumento deste espaçamento ao variar a concentração de tensoativo de 20 para 30\%. Assim, para o teste de Inchamento de Foster, optouse por aditivar os meios analisados com a argila organofílica de menor custo, ou seja, a que apresenta menor concentração de tensoativo, $20 \%$.

$\mathrm{Na}$ Tabela 3, estão apresentados os resultados dos inchamentos de Foster, com e sem agitação, das argilas organofílicas tratadas com os tensoativos Ultranex NP40, Tween 80 e Praepagen, nos meios parafina (óleo mineral), microemulsão A/O de parafina, óleo de pinho (óleo vegetal) e microemulsão $\mathrm{A} / \mathrm{O}$ de óleo de pinho.

Tabela 3: Inchamento de Foster das argilas organofílicas.

\begin{tabular}{|c|c|c|c|c|}
\hline Meio & Agitação & Ultranex NP 40 & Tween 80 & Praepagen \\
\hline Parafina & Sim & $\begin{array}{c}2 \mathrm{~mL} / \mathrm{g} \\
\text { Não inchamento } \\
2 \mathrm{~mL} / \mathrm{g} \\
\text { Não inchamento }\end{array}$ & $\begin{array}{c}2 \mathrm{~mL} / \mathrm{g} \\
\text { Não inchamento } \\
2 \mathrm{~mL} / \mathrm{g} \\
\text { Não inchamento }\end{array}$ & $\begin{array}{c}2 \mathrm{~mL} / \mathrm{g} \\
\text { Não inchamento } \\
2,5 \mathrm{~mL} / \mathrm{g} \\
\text { Inchamento baixo }\end{array}$ \\
\hline $\begin{array}{c}\text { Microemulsão } \\
\text { com parafina }\end{array}$ & Sim & $\begin{array}{c}- \\
39 \mathrm{~mL} / \mathrm{g} \\
\text { Inchamento alto }\end{array}$ & $\begin{array}{c}- \\
30 \mathrm{~mL} / \mathrm{g} \\
\text { Inchamento alto }\end{array}$ & $\begin{array}{c}- \\
79 \mathrm{~mL} / \mathrm{g} \\
\text { Inchamento alto }\end{array}$ \\
\hline Óleo de Pinho & Não & $\begin{array}{c}3 \mathrm{~mL} / \mathrm{g} \\
\text { Inchamento baixo } \\
2,8 \mathrm{~mL} / \mathrm{g} \\
\text { Inchamento baixo }\end{array}$ & $\begin{array}{c}3 \mathrm{~mL} / \mathrm{g} \\
\text { Inchamento baixo } \\
2 \mathrm{~mL} / \mathrm{g} \\
\text { Não inchamento }\end{array}$ & $\begin{array}{c}6 \mathrm{~mL} / \mathrm{g} \\
\text { Inchamento alto } \\
4,2 \mathrm{~mL} / \mathrm{g} \\
\text { Inchamento baixo }\end{array}$ \\
\hline $\begin{array}{c}\text { Microemulsão } \\
\text { com óleo de } \\
\text { pinho }\end{array}$ & Não & $\begin{array}{c}- \\
3 \mathrm{~mL} / \mathrm{g} \\
\text { Inchamento baixo }\end{array}$ & $\begin{array}{c}- \\
2,5 \mathrm{~mL} / \mathrm{g} \\
\text { Inchamento baixo }\end{array}$ & $\begin{array}{c}- \\
4 \mathrm{~mL} / \mathrm{g} \\
\text { Inchamento baixo }\end{array}$ \\
\hline
\end{tabular}


As leituras sem agitação para a microemulsão não foram realizadas, pois a microemulsão apresentou viscosidade elevada, impossibilitando a sedimentação da bentonita. Por esse motivo realizou-se apenas as leituras com agitação.

Analisando a Tabela 3, verifica-se a baixa afinidade pelo meio dispersante de parafina, o que já era previsto de acordo com os trabalhos de Ferreira (2009) e Silva et al., (2012), nos quais foi analisada a afinidade da parafina com diversos tipos de argilas bentoníticas, organofilizadas por diferentes tensoativos (iônico e não iônico). Porém, para a microemulsão A/O com parafina, foram observados valores de inchamento muito elevados. Essa magnitude dos resultados pode ser justificada pela alta viscosidade do meio e alta interação química do sistema microemulsionado formado e da argila organofílica. Além disso, pode-se destacar, através dos resultados, que a argila modificada com Praepagen apresenta maior interação com este meio (Figura 8), concordando com a maior distância interplanar indicada pela difração de raios $X$.

Investigando o inchamento no óleo vegetal, observa-se pela Tabela 3 que, tanto o inchamento da argila no óleo de pinho puro quanto na microemulsão $A / O$ de óleo de pinho, não houve inchamento significativo, para todos os tensoativos testados. Este resultado é decorrente da falta de interação entre a estrutura do óleo de pinho, da micela A/O de óleo de pinho e da argila organofílica. As forças moleculares formadas entre os componentes são baixas ou inexistentes, impedindo o inchamento da argila, mesmo em um meio viscoso, como é o caso da microemulsão.

Assim, apenas a microemulsão de parafina é adequada para ser a base de um fluido de perfuração microemulsionado do tipo $\mathrm{A} / \mathrm{O}$, pois, com o alto inchamento da argila, esta poderá suspender os aditivos do fluido, tais como a barita $\left(\mathrm{BaSO}_{4}\right)$ e, com a interação entre os compostos, haverá a formação de um fluido de perfuração homogêneo, com viscosidade e tixotropia satisfatórios.

A Figura 9 mostra o melhor resultado obtido para o inchamento de Foster, apresentado pelo sistema formado pela microemulsão com parafina e o tensoativo Praepagen.

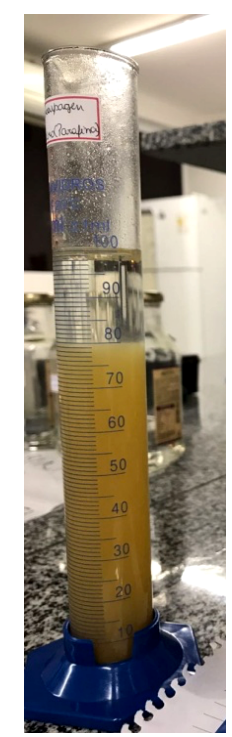

Figura 9: Teste de inchamento de Foster com argila bentonita organofilizada com Praepagen em meio dispersante do sistema I. 


\section{CONCLUSÃO}

1- Os diagramas de fases ternários I e II apresentaram regiões de microemulsão que permitiram formular sistemas do tipo microemulsão $A / O$, essenciais para a obtenção de fluidos de perfuração base microemulsionada.

2- A análise de difração de raios X (DRX) mostrou que todos os tensoativos utilizados provocaram aumento na distância interplanar, quando comparados com a argila in natura, sendo o tensoativo Praepagen o que apresentou melhor resultado para este parâmetro.

3-O teste de enchimento de Foster mostrou que a microemulsão com n-parafina apresentou afinidade com todas as argilas modificadas, sendo a argila organofilizada com Praepagen a de maior interação, resultando no maior enchimento; o que leva a concluir que a microemulsão de parafina é a mais adequada para ser a base de um fluido de perfuração microemulsionado do tipo A/O.

\section{REFERÊNCIAS}

Almeida, R. D. F. \& Silva, W. G. A. L. (2010). Avaliação de fluido de perfuração de base aquosa contendo poliglicóis modificados. Trabalho Final de Curso de Engenharia do Petróleo. Universidade Federal do Rio de Janeiro, Rio de Janeiro, RJ, Brasil.

American Petroleum Institute (1979). Glossary of drilling fluid and associated terms (2a ed.). Bulletin D 11.

Araújo, B. S. A. (2015). Estudo da caracterização de glicerina e seu potencial uso como base para fluido aquoso. Dissertação de mestrado, Universidade Estadual do Norte Fluminense, Macaé, RJ, Brasil.

Aum, Y. K. P. G. (2016) Sistemas microemulsionados visando à remoção de depósitos parafínicos. Tese de doutorado em Engenharia Química, Universidade Federal do Rio Grande do Norte, Natal, RN, Brasil.

Barbosa, R., Araujo, E. M., Oliveira, A. D. \& Melo, T. J. A. (2006). Efeito de sais quaternários de amônio na organofilização de uma argila bentonita nacional. Revista Cerâmica, 52, 264 - 268.

Caenn, R. \& Chilingar, G. V. (1996). Drilling fluids: state of the art. Journal of Petroleum Science and Enginnering, 14, 221-230.

Curbelo, F. D. S., Garnica, A. I. C., Freitas, J. C. O., Sousa, R. P. F. \& Braga, G. S. (2016). Desenvolvimeno e características de um fluido de perfuração microemulsionado a base de glicerina. Patente do Instituto Nacional da Propriedade Industrial No. BR1020160190487.

Curbelo, F. D. S., Garnica, A. I. C., Sousa, R. P. F., Queiroz, I. X., Araujo \& E. A. (2017). Composição de um lubrificante biodegradável a base de microemulsão para aplicação em fluidos de perfuração. Patente do Instituto Nacional da Propriedade Industrial No. BR1020170015980.

Daltin, D. (2011). Tensoativos: química, propriedades e aplicações (pp. 327). São Paulo: Blucher. 
Damasceno, B. P. G. L., Silva., J. A., Oliveira, E. E., Silveira, W. L. L., Araújo, J. B., Oliveira, A. G. \& Egito, E. S. T. (2011). Microemulsão: um promissor carreador para moléculas insolúveis. Journal of Basic and Applied Pharmaceutical Sciences, 32(1), 9 - 18.

Dantas Neto, A. A., Fernandes, M. R., Barros Neto, E. L., Dantas, T. N. C. \& Moura, M. C. P. A. (2011). Alternative fuels composed by blends of nonionic surfactant with diesel and water: engine performance and emissions. Brazilian Journal of Chemical Engineering, 28(03), 521 $-531$.

Davies, S. N., Meeten, G.H. \& Way, P. W. (1997). Water based drilling fluid additive and methods of using fluids containing additives. Patente do United States Patent No. 5652200.

Ferreira, H. S. (2009). Otimização de processo de organofilização de bentonitas visando seu uso em fluidos de perfuração não aquosos. Tese de doutorado em Engenharia de Processo, Universidade Federal de Campina Grande, Campina Grande, PB, Brasil.

Foster, M. D. (1953). Geochemical studies of clay minerals. (II) Relation between ionic substitution and swelling in montmorillonite apud FERREIRA, 2009.

Hayes, J. B., Haws, G. W. \& Gogarty, W. B. (1977, março). Water-in-oil microemulsion drilling fluids. Patente do United States Patent No. 4012329 A.

Ho, H. O., Hsiao, C. C. \& Sheu, M. T. (1996). Preparation of microemulsions using polyglycerol fatty acid esters as surfactant for the delivery of protein drugs. J Pharm Sci, 85(2), 138 - 143.

Martins, A. B., Ferreira, H. S., Ferreira H. C. \& Never, G. A. (2007, outubro). Desenvolvimento de argilas bentoníticas organofilizadas para uso em fluidos não aquosos de baixo conteúdo aromático. Congresso Brasileiro de P\&D em Petróleo e Gás, Campinas, SP, Brasil, 4.

Morais, R. B., Silva, A. S. \& Silva, D. C. (2017, junho). Utilização da difração de raios X na caracterização de uma amostra de argilomineral. Congresso nacional de pesquisa e ensino em ciências, Campina Grande, PB, Brasil, 2.

Paiva, L. B. e Morales, A. R. (2007, junho). Avaliação de argilas bentonitas nacionais e argentinas quanto ao potencial de obtenção de argilas organofílicas visando à aplicação em nanocompósitos poliméricos. Anais do Congresso Brasileiro de Cerâmica, Salvador, BA, Brasil, 51.

Paiva, L. B., Morales, A. R. \& Diaz, F. R. V. (2008). Argilas organofílicas: características, metodologias de preparação, compostos de intercalação e técnicas de caracterização. Revista Cerâmica, 54(330), 213 - 226.

Pereira, K. R. O., Cabral, S. B., Rodrigues, M.G. F., Valenzuela Diaz, F. R. \& Rodrigues, M. G. F. (2007). Síntese e caracterização de argilas organofílicas: comparação no uso de dois métodos. Revista Eletrônica de Materiais e Processos, 2(2), 01 - 08.

Quintero, L., Jones, T. A., Clark, D. E. \& Schwertner, D. (2009). Cases History Studies of Production Enhancement in Cased Hole Wells Using Microemulsion Fluids. Society of Petroleum Engineers. SPE, 121926.

Rossi, C. G. F. T., Dantas, T. N. C., Dantas Neto, A. A. \& Maciel, M. A. M. (2007). Microemulsões: uma abordagem básica e perspectivas para aplicabilidade industrial. Revista Universidade Rural Ser Ciências Exatas e da Terra, 26(1-2), 45 - 66. 
Santos, C. P. F., Melo, D. M. A., Melo, M. A. F. \& Sobrinho, E. V. (2002). Caracterização e uso de argilas bentonitas e vermiculitas para adsorção de cobre (II) em solução. Revista Cerâmica, 48(308), 178 - 182.

Santos, P. S. (1989). Ciência e Tecnologia de Argilas (Vol. 1, 2a ed., pp. 500). São Paulo: Blucher.

Shiroma, P. H. (2012). Estudo do comportamento reológico de suspensões aquosas de bentonita e cmc: influência na concentração do NaCl. Dissertação de Mestrado em Engenharia Química, Escola Politécnica da Universidade de São Paulo, São Paulo, SP, Brasil.

Silva, A. R. V. e Ferreira, H. S. (2008). Argilas bentoníticas: conceitos, estruturas, propriedades, usos industriais, reservas, produção e produtores/fornecedores nacionais e internacionais. Revista Eletrônica de Materiais e Processos, 3(2), 26 - 35.

Silva, I. A., Costa, J. M. R., Ferreira, H. S., Menezes, R. R., Neves, G. A \& Ferreira, H. C. (2012). Organofilização de argilas bentoníticas com tensoativos não-iônicos visando seu uso em fluidos de perfuração base óleo. Revista Cerâmica, 58(347), 317 - 327.

Son, M.O. (1973). Use of micellar dispersions as drilling fluids. Patente do United States Patent Office No. 3734856A.

Thomas, J. E. (2001). Fundamentos de Engenharia de Petróleo (pp. 271). Rio de Janeiro: Interciência. 